\title{
ENTRE DEMANDAS E DESEJOS: NECESSIDADE INFORMACIONAIS DE JORNALISTAS NO CENÁRIO DE JORNAIS PARAIBANOS
}

\author{
Andréia Gomes de Azevedo \\ Orientanda \\ andreia.azevedo@hotmail.com \\ Prof $^{a}$ Doutora Marynice de Medeiros Matos Autran \\ Orientadora \\ $D C I / P P G C I / U F P B$
}

\section{Resumo}

Os estudos sobre jornalistas, enquanto usuários da informação, são escassos no Brasil. Apesar desses profissionais terem como objeto de trabalho a informação, a literatura aponta que o estudo sobre suas necessidades, uso, acesso, barreiras etc., não tem despertado o devido interesse dos pesquisadores para explorar essa temática. Esta pesquisa se propõe a analisar as necessidades informacionais dos jornalistas que trabalham no Jornal da Paraíba, Correio da Paraíba, G1 da Paraíba e Jornal A União. A pesquisa caracteriza-se como descritiva e exploratória, com abordagens quantitativa e qualitativa. Utilizou como instrumento de coleta de dados, o questionário. Os resultados apontam que: os sujeitos, em sua grande maioria, pertencem ao sexo feminino; a faixa etária prevalecente se encontra no intervalo entre 26 e 35 anos; utilizam com maior intensidade as seguintes fontes: Oficial, Institucional, Testemunhal, Especializada e Internet; buscam com maior frequência materiais informacionais digitais, para a produção de notícias. Os resultados revelam, também, que a restrição à informação é considerada a principal barreira/obstáculo enfrentada. A credibilidade e interesse público são os critérios que mais utilizam para a seleção de informação. Há unanimidade quanto a influência das tecnologias de informação na alteração do comportamento informacional, notadamente no que se refere ao comportamento de busca da informação.

Palavras-chave: Necessidade de Informação. Usuário da Informação. Jornalistas. 